\title{
EL PROYECTO EDUCATIVO-ILUSTRADO DE KANT
}

\author{
Dra. María Isabel Lafuente Guantes ${ }^{1}$ \\ Universidad de León - España \\ Grupo de Investigación HISULA \\ milafg@unileon.es
}

Recepción: 30/05/2008

Evaluación: 02/07/2009

Aceptación: 14/09/2009

Artículo de Reflexión

\section{RESUMEN}

Los objetivos de este comentario de texto son analizar y poner en relación las principales ideas pedagógicas que constituyen el proyecto educativo de Kant. El método fenomenológico que se pone en práctica, permite encontrar su idea esencial, la de naturaleza humana, examinar cómo la concibe el autor, así como mostrar cuáles son las formas educativas que corresponden a sus dos aspectos constitutivos (corporal y espiritual), y cómo se relacionan entre sí para configurar el proyecto educativo ilustrado de este autor. Por último, se examinan los límites y limitaciones tanto históricos, como actuales que presenta.

El texto kantiano es una clara muestra de que este conocimiento es inevitable, es decir, de que si se pretende lograr un proceder pragmáticamente satisfactorio, la pregunta ¿qué puedo hacer?, exige tener una respuesta a la pregunta ¿qué puedo conocer?, y no sólo porque como idealista Kant entienda que la práctica depende de la teoría sino, sobre todo, porque supone que sin un modelo, que sólo la teoría puede proporcionar, es imposible lograr un proceso que alcance éxito alguno, pues sólo aquél es capaz de permitir decidir qué aceptar, qué negar o qué variar en la acción.

Según Kant sólo la conciencia moral puede lograr hacer de un individuo un buen hombre y un buen ciudadano, pues sólo cuando ésta se ha formado puede alcanzar

\footnotetext{
1 Doctora en Filosofía y Letras por la Universidad de Oviedo. Catedrática de Universidad del Área Filosofía. Licenciatura, Universidad Complutense de Madrid, dos sexenios de investigación y seis quinquenios docentes. Actualmente es miembro del Grupo de Investigación Historia y Prospectiva de la Universidad Latinoamericana HISULA.
} 
aquél a pensar una religión que no se haya fundada en la superstición, sino en el conocimiento de las leyes divinas, descubrir el bien en el mal, y la igualdad entre los hombre tras la desigual ante las leyes civiles, o los avatares de la fortuna.

Palabras clave: Educación, Educación-Mecánica, Educación-Moral, Libertad, Método Fenomenológico.

\title{
KANT'S EDUCATIONAL-ILLUSTRATED PROJECT
}

\author{
Dra. María Isabel Lafuente Guantes \\ Universidad de León - España \\ HISULA Research Group \\ milafg@unileon.es
}

\begin{abstract}
The aim of this text commentary is both to analyze and organize the main pedagogic ideas that constitute Kant's educational project. The phenomenological method used by him, allows to find out his essential idea and of the human nature, and to examine how the author conceives it as well as to show the educational forms that make possible education in its two components (body and mind), and how they work together to shape the educationally illustrated project of this author. Finally, the article examines the past and current limits and limitations in this project.
\end{abstract}

Key Words: Education, Mechanical-Education, Moral-Education, Liberty, Phenomenological method. 


\section{INTRODUCCIÓN}

La obra de Immanuel Kant se considera la cumbre del siglo XVIII europeo, período que forma parte de la Edad Moderna, y es conocido históricamente bajo la denominación de "Ilustración." Las ideas gestadas en ese momento de la Historia han ejercido sobre la humanidad una de las influencias más poderosas que ha tenido lugar en el campo de la educación, y en general del conocimiento y actividad humana. Esta influencia llega hasta el punto de que la simple mención de éste nombre sirve para suscitar todo tipo de sentimientos relacionados con la necesidad de cambio, superación y progreso, pero realmente el fenómeno ilustrado es muy complejo y su conocimiento no se puede reducir al que es capaz de proporcionar una definición, sino que requiere examinar en detalle los distintos procesos que tuvieron lugar en el campo, aún indistinto o muy poco delimitado, de distintas ciencias que, sin embargo, inciden todas en la ciencia del hombre,

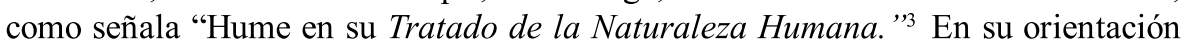
filosófica estos procesos han aportado concepciones tan importantes como: el empirismo, el enciclopedismo o el idealismo trascendental.

La influencia de Kant es en este caso fundamental, pues no sólo fijó de forma magistral los principios que guiaban el proyecto ilustrado en su obra: ¿Qué es la Ilustración?, sino que en otra pequeña obra de la que vamos a ocuparnos "Pedagogía,"4 expuso de forma sucinta, pero muy densa, las principales ideas que debían servir de orientación a un proyecto educativo ilustrado, siendo éste aquél capaz de aunar las condiciones naturales del individuo, con el desarrollo de su conocimiento, de ideas propias, de comportamiento moral, y con la generación de reglas del gusto. Mediante la educación de las capacidades individuales, éste proyecto pretende alcanzar a conciliar los intereses privados (subjetivos) con los fines universales que exige el Estado y la humanidad, haciendo posible que el individuo sea capaz de lograr un mejor conocimiento y comportamiento moral, que socialmente se alcance un mayor bienestar, y que el ser humano, como partícipe de la idea de humanidad, alcance una mayor perfección.

Como en este trabajo vamos a realizar un "comentario sobre un texto", de la Pedagogía de Kant, considero necesario señalar, al menos someramente, algunos de

\footnotetext{
2 Ilustración es el término genérico con que se designa el proceso general, pero éste incluye una enorme variedad y diversidad de procesos: filosóficos, económicos, literarios, antropológicos, educativos, sociales, políticos e históricos, que tuvieron lugar en el Siglo XVIII, y que tenían como objetivo fundamental eliminar el carácter dogmático de toda investigación y enseñanza. A este siglo se le denomina genéricamente Siglo de la Ilustración o Ilustrado, pero el proceso general adquirió según los países denominaciones diferentes, así en España se habla de Siglo de las Luces, en Francia de habla de Les Lumières, y en Alemania de Aufklärung.

3 Hume indica expresamente en la Introducción a su Tratado que es necesario estudiar en qué consiste la Naturaleza Humana de la que se preocupan diversas ciencias como la Epistemología, la Lógica, la Antropología etc. Cfr. Hume, D. (1923): Tratado de la Naturaleza Humana. Madrid, Calpe, p. 13.

4 KANT, I. (1983): Pedagogía. Madrid, Akal.

5 El texto que figura en el anexo 1 es: Kant, I. (1983): "Tratado" en: Pedagogía. Madrid, Akal, pp. 45-66.
}

Rhela. Vol. 13. Año 2009, pp. $241-264$ 
los problemas que plantea la obra pedagógica de este autor, así como el método que vamos a seguir. Las lecciones sobre pedagogía que Kant impartió en la Universidad de Könisberg durante el primer semestre (invernal) de los años 1776-1777, 1783-1784, 1786-1787, y en el segundo semestre (estival) del año 1780, no fueron publicadas por él, sino que, en 1803, se publicó la recopilación que realizó su discípulo Friedrich Theodor Rink, lo que ha suscitado el problema de cómo entender la correspondencia entre las ideas pedagógicas presentes en esta obra y las de los dos períodos en que, en general, se clasifican sus escritos: pre-crítico y crítico.

Si se atiende al año de la publicación de esta obra (1803), hay que considerar que pertenece al período crítico; pero si se consideran los años en que estas lecciones se impartieron, habría que considerar que son posibles dos lecturas: una relativa al período pre-crítico, pues, dada la fecha en que se comenzaron a impartir, sus ideas estarían en relación con las presentes en las obras de este período, que comienza en 1740 y se cierra, en lo que afecta a sus grandes obras, con la Dissertatio de 1770, pero que se alarga en lo que respecta a educación hasta 1776-1777, fecha de publicación de los artículos relativos al Instituto Filantrópico de Dessau; la otra tendría que atender a la impartición de las lecciones en el período crítico (1777-1786). Por tanto, ponerse en relación con obras como los Prolegómenos a toda metafisica futura, la Crítica de la Razón Pura, la Crítica de la Razón Práctica y la Crítica del Juicio. Esta situación se complica si se entiende que en el pensamiento kantiano no hay dos sino tres períodos, y se añade un período post-critico que separa la primera concepción crítica, la de la Crítica de la Razón Pura, de las otras dos críticas, la Crítica de la Razón Práctica y la Crítica del Juicio.

La obra pedagógica de Kant nos proporciona sus ideas sobre el arte de enseñar ${ }^{6}$, que es como él consideró la educación; ahora bien, estas ideas pueden servir a un doble propósito: como base para establecer el contenido de una o unas asignaturas, o como capaces de mostrar en qué debe consistir un programa educativo, es decir, cuáles deben

\footnotetext{
6 Cuando Kant se refiere a la enseñanza no habla ni de ejercicio, ni de hábito, sino de arte; la razón de ello es compleja, pero puede significarse lo siguiente: 1. Que tanto el ejercicio como el hábito solo hacen relación a una educación reiterativa, y excluyen la enseñanza innovadora, que es la que Kant propicia en moral. 2. Que la noción de arte permite referirse tanto a la necesidad de educar al individuo, como a la de fijar las reglas necesarias para la educación del género humano, lo que concuerda mucho mejor con el ideal ilustrado de nociones que solo implican condiciones psicológicas. 3. Que con la noción de arte Kant intenta mostrar que es posible establecer las reglas que permiten una educación pública (que es obra de generaciones y de una revolución continua, pero posible), que atienda al individuo y su perfección (logro de criterios propios y maduros), no sólo a su instrucción. En esta defensa Kant se opone, no a un dirigismo educativo estatal (que descarta de antemano), sino a que se deje a la educación privada la educación moral. Considera insuficiente esa educación, por una parte, porque es sólo para unos pocos, por otra, porque está ligada a preceptores (Kant lo fue) y a caprichos familiares, y no se preocupa en educar ciudadanos, de encauzar la educación en beneficio del progreso tanto del individuo como del Estado, sino de uno, o del otro. Ahora bien, ciertamente Kant sostuvo que la financiación de la enseñanza pública no debía ser estatal, sino ligada a esfuerzos de los particulares, oponiéndose explícitamente a la idea de Basedow, pues éste pretendía que dependiera de la cooperación de los príncipes, de forma que se orientara al bien del Estado, pero no al del individuo. (Ver: Kant. I. Pedagogía, p. 37).
} 
ser sus principios y su finalidad ${ }^{7}$. Las ideas kantianas pueden realizar ambos, por ello considero necesario que el lector sepa que, en el comentario de texto que nos proponemos realizar, vamos a atender a las ideas pedagógicas de Kant, no como la base para establecer el contenido de unas o varias asignaturas en una Facultad de Educación, sino como aquellas capaces dar sentido al proceso educativo mostrándolo como proyecto educativo ilustrado, lo que tiene que basarse en su capacidad para dar respuesta a preguntas tan fundamentales como: ¿qué educar?, ¿por qué y para qué educar? o ¿cómo educar? En cuanto estas preguntas inciden en el conocimiento de lo que el ser humano es, su respuesta requiere establecer, a partir de los términos fundamentales que constituyen el ámbito filológico del texto kantiano, aquellos conceptos que permiten entender su propuesta educativa y mostrar su unidad, así como examinar críticamente su viabilidad y consistencia, tanto en lo que afecta a su consideración histórica, como a sus valores actuales.

El método kantiano es crítico-transcendental. El que nos proponemos seguir es fenomenológico, digno heredero suyo, que permite poner de relieve la idea sin la que no es posible ordenar y entender con sentido los conceptos empíricos presentes en el texto. Para lograrlo, es necesario aislar estos conceptos (epojé) para, regresando más allá de ellos, poder mostrar críticamente en qué términos filosóficos se apoyan; así como dar lugar a examinar los problemas históricos que comportan, y permitir un nivel constructivo que haga posible saber sobre la transcendentalidad de los conceptos que la obra proporciona.

\section{El autor y la obra}

Immanuel Kant nació en 1724 en Königsberg, capital de la Prusia Oriental, que en el siglo XX se convirtió en Kaliningrado (Rusia); en esa ciudad trascurrió toda su vida. Su padre, que se llamaba Johann Georg Kant, y su madre, Anna Regina Porter, le educaron en el pietismo, una de las formas más rigurosas del protestantismo, que ponía énfasis en la devoción religiosa, la humildad personal y la interpretación literal de la Biblia. Estudió en el Collegium Fridericianum y, a partir de 1740, en la Universidad de Königsberg, donde estudió con el profesor Martin Knutzen, racionalista que le introduce en la filosofía de Leibniz y Wolff, en la filosofía británica en general y, particularmente, en la física de Newton. A partir de 1746 Kant se convirtió en un profesor particular en los pequeños pueblos alrededor de Königsberg, pero siguió investigando. En 1749 publicó su primera obra filosófica, Meditaciones sobre la verdadera estimación de las fuerzas vivas (Gedanken von der wahren Schätzung der lebendigen Kräfte), y desde entonces hasta su muerte, el 12 de febrero de 1804, publicó "consecutivamente numerosas e importantes obras" en las que funda el concepto de Filosofia Crítica, con el que se conoce tanto su teoría del conocimiento, su teoría moral, como su estética, pedagogía y teoría de la historia. Este concepto caracteriza completamente su sistema original de pensamiento que recibe el nombre de Idealismo Transcendental, y que tiene lugar como sistema filosófico genérico en cuanto a él se sumaron numerosos filósofos.

\footnotetext{
7 Dado que hoy se considera que el término currículo es polisémico resulta aplicable a ambos propósitos.

8 Véase apartado 5.3, Cronología del autor, en los Anexos.
} 
La Filosofia Crítica desarrollada por Kant constituye una aportación fundamental en el conjunto de los trabajos ilustrados, estén orientados a la educación, la antropología, la historia, la economía, etc., en tanto establece que la base de todo progreso de la humanidad se encuentra, no como señalaba Hume en la capacidad del ser humano para lograr ideas generales, sino en su capacidad para transformar la conciencia, porque la virtud de las ideas no es la de servir para diferenciar, según grado, el conocimiento humano del instinto animal, así como el comportamiento humano del puramente animal, sino la de permitir distinguirlos totalmente, pues sólo el hombre puede conseguir, ejercitando su libertad, lograr ideas que instauren nuevos significados y varien los dados, lo que le permite saber sobre distintos estados de las cosas, sobre cómo entender, ordenar y utilizar las cosas de forma distinta, y mejor, siendo esto lo que de hecho posibilita hablar con fundamento sobre la realidad del progreso humano.

Esta condición, que constituye la principal aportación (aunque haya muchas más) de la Filosofia Crítica, se manifiesta de forma muy importante en sus Lecciones sobre Pedagogía, que es la obra de la que vamos a comentar uno de sus textos más significativos. En la traducción de esta obra al español que vamos a utilizar y que, como hemos significado, sigue las ediciones alemanas publicadas sobre los apuntes de su discípulo Dr. Rink, aparecen cuatro partes fundamentales: 1. Introducción, en la que Kant establece los principios generales que considera necesarios para entender qué es y supone la educación; 2. Tratado, breve texto en el que resume programáticamente las partes que debe comprender la educación, así como la finalidad de cada una; 3. la titulada De la educación fisica, en la que considera los cuidados que deben prestarse al niño, y su influencia en la buena educación de las emociones y de la voluntad y, por último, 4. De la educación práctica, en que expone la forma de lograr que el ser humano desarrolle su razón y una estima propia (autoestima), no por las pasiones que su comparación con otros pueda suscitar, sino por haber logrado una habilidad sólida para hacer y conocer las cosas, un temperamento prudente que le permita enfrentar situaciones negativas, y un carácter moral que le permita saber cuál es su deber para consigo mismo y para con los demás, por haber alcanzado una capacidad para saber hacer, conocer y comportarse, que se traduzca en lograr extraer de la naturaleza de las cosas el mejor fin posible y ordenarlas conforme a él.

La obra contiene, así mismo, cuatro apéndices que corresponden a los Artículos, relativos al Philantropinun (Aufsätze, das Philantropin betreffend), que Kant publicó en su período pre-crítico en 1776-1777. En los dos primeros expone sus ideas relativas a la importancia para la educación del Instituto Filantrópico establecido en la ciudad de Dessau, por Basedow, ${ }^{9}$ en el tercero y el cuarto se recogen las primeras exposiciones

\footnotetext{
9 Johann Bernhard Basedow, nació en Hamburgo en 1724 y murió en 1790. Escribió en otras obras: Apelación a un amigo de la humanidad y a los hombres de poder en relación con las Escuelas y Estudios y su influencia en el Bienestar Público (1768); El Libro Método para Padres y Madres de Familias y de Naciones (1770) y en 1774 la Elementarwerk. Fue contratado por el Príncipe Leopoldo de Anhald-Dessau para abrir una escuela experimental El Philanthropinum, que fue inaugurado en 1774. Las ideas educativas principales de Basedow, muy influenciadas por la Ilustración, parten del supuesto de que hay que educar a los
} 
de sus ideas educativas referentes a la habilidad, prudencia y moralidad, que relaciona con la expuestas por Rousseau en su "Emilio" "10 y sus ideas relativas a la relación entre la enseñanza de la religión y la moralidad.

El contenido de la obra sobre pedagogía de Kant, muestra que recogió las ideas pedagógicas más liberales de la época, y las hizo suyas; su forma de exposición es escueta y a veces casi clasificatoria, por lo que para el conocimiento preciso de los conceptos que usa, y para la delimitación de los problemas que ha de solventar para lograrlos, se requiere situarlas en el conjunto de su obra. Y, es que, ciertamente, la teoría de la educación kantiana resulta un ejercicio de sus ideas filosóficas puestas en relación con las obras pedagógicas de los ilustrados, de manera que una lectura profunda de la obra requiere conocer sus ideas relativas a conceptos como: ilustración, libertad, conocimiento, gusto, religión y, por tanto, seguirlas en las tres críticas ya mencionada, en la antropología, y en sus obras sobre religión y política, en que se desarrollan tesis tan sólo enunciadas en la Pedagogía, como la necesidad de que sea la moral la que lleve al individuo a un pensamiento religioso, y no a la inversa, que sea la religión la que funde la moral.

\section{Comentario de Texto}

\subsection{Idea principal e idea secundaria}

"El texto que hemos seleccionado"11 pertenece a la segunda parte de la Pedagogía, y lleva por título: Tratado. Si se atiende analíticamente al texto, se muestra que sus distintas ideas confluyen en una idea principal, la que responde a la pregunta: ¿Qué es la Pedagogía o Teoría de la Educación? Esta idea era en la época kantiana, y sigue siéndolo en la actualidad, una idea muy conflictiva que requiere para su conocimiento un análisis histórico de los tratados de los diferentes autores que se han preocupado por determinar los principios que deben guiar la educación, pero también, y sobre todo, cuando se trata de entender puntualmente el texto, de esclarecer qué idea de ser humano y de sociedad sostiene el autor.

Esta pregunta no aparece formulada expresamente en este pequeño texto, sino que está elidida, pero es evidentemente la que se propone responder Kant, la que funda como principio el texto, y a la que obedece su primera línea cuando dice de manera explícita: "La Pedagogía o Teoría de la Educación es....." 12 Ahora bien, su respuesta muestra que el sentido de la pregunta no es el de preocuparse directamente por la

\footnotetext{
individuos, por lo que es necesario atender prioritariamente a sus determinantes psicológicas, y que la educación debe estar orientada a lograr la autodeterminación del alumno. Defensor de una concepción atomista de la sociedad, sostenía que la única forma de lograr un Estado que pudiera alcanzar el bienestar, era educar bien a los individuos, pues aquél no era más que la comunidad de los individuos.

${ }^{10}$ ROUSSEAU, E. (2007): Emilio, o de la educación, Madrid, Alianza Editorial.

11 Véase el texto en el apartado 5, Anexos, pp. 16-17 de este trabajo.

12 Kant, I. Op. Cit. p. 45.
}

Rhela. Vol. 13. Año 2009, pp. $241-264$ 
esencia de la educación, lo que requeriría una respuesta en que se diera cuenta de las ideas que han existido y de las existentes, indicando cómo considerarlas, cuáles aceptar, cuáles rechazar, y por qué, así como cuál es la posición que adopta el autor dados los planteamientos hechos; no considera, por ejemplo, si la teoría de la educación tiene que partir de saber cómo entender lo humano, para saber cómo atenderlo, sino que, por el contrario, su respuesta es totalmente pragmática, guiada simplemente por la consideración de que está tratando una materia en que se tienen que ejercitar unas ideas, no especular sobre ellas, y que, por tanto, la respuesta debe establecer de forma inmediata los campos en que ese ejercicio es necesario, es decir, en los que hay que aplicar aquellas ideas que permitan saber cómo proceder en educación. Por ello, la respuesta a qué es la educación sólo expresa que ésta es “...o fisica o práctica," siendo la fisica aquella que se ocupa de los cuidados, y la práctica la que se ocupa de la educación moral.

La clasificación de Kant es confusa, pues no sólo une y distingue reiteradamente cuidado y educación, moral y práctica, etc., sino que en ella introduce variantes a lo largo del texto cuyas relaciones, que no están expresadas, hay que mostrar para facilitar su comprensión. Pero, es posible establecer la estructura del texto entendiendo que consta de una idea principal y una secundaria, que pueden ordenarse en la forma de secuencia subordinada. En la idea principal se establece que la educación es: fisica / moral (práctica), y se explica cómo entender ésta oposición; en la idea secundaria se expone en qué consiste la educación física y en qué la moral: física-cuidados / práctica (moral)-formación escolástico-mecánica, formación pragmática y formación moral, y la razón de su necesidad; esto según su exposición inicial. El esquema correspondiente es el siguiente:

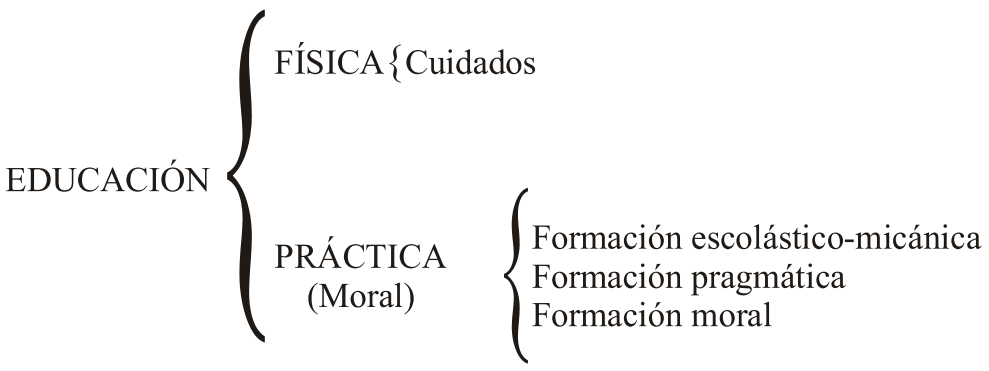

Esquema (1)

El texto presenta una dificultad añadida a la subordinación de las ideas que es la siguiente: que la idea principal sólo enuncia que los cuidados tienen que ver con la parte animal del hombre, y la práctica con la libertad, lo que hace necesario saber qué tiene en común el ser humano con los animales, o qué tipo de animal es, así como qué

13 Ibídem, p. 46. 
es la libertad, qué tipo de seres nos hace y se espera que seamos, lo que requiere referir el texto al contexto general de la obra y, como pronto se aprecia al realizarlo, al resto de la obra kantiana, al menos a las obras del período crítico. Esto permite afirmar que para comentar el texto no solo son necesarias las ideas que tienen lugar en su exposición empírica (literalidad), sino también aquellas que son exigidas para comprenderlas, independientemente de que para saber sobre ellas no podamos limitarnos a lo enunciado en el texto, y se requiera una lectura más amplia. Intentaremos recoger estas ideas mostrándolas como referencias obligadas, al menos, para no extendernos de forma excesiva.

Lo que hasta el momento hemos señalado sobre el texto nos permite considerar que en él se trata de dirimir de forma prioritaria qué hacer en educación, dicho de otra forma, que la teoría de la educación tiene que decirnos en qué tiene que consistir la práctica educativa. Pero, como para lograrlo es necesario regular la práctica, es saber cómo regularla lo que suscita la necesidad de saber qué es verdaderamente educación, es decir, que es saber cómo regular la práctica educativa lo que exige el conocimiento de la esencia o, dicho de otro modo, el conocimiento de aquellas ideas, y de la forma de establecer relaciones entre ellas, que se muestren como inevitables a la hora de lograr que el ser humano supere el nivel natural y, sin prescindir de él, pueda alcanzar un estado de mayor igualdad ( moralidad).

El proceder de Kant es una interesante y clara muestra del problema por el que siglos después se preocupará "G. S. Peirce" 14 cuando, al interesarse desde la pragmática por la verdad, y considerar que ésta se entiende de forma inmediata en función de la utilidad y el éxito, perciba y considere necesario introducir al lector en que saber sobre la verdad en sentido pragmático, y conseguir alcanzarla en una aplicación, no sólo no exime, sino que exige, el conocimiento de aquellos principios o ideas que la hacen factible.

\subsection{Análisis del texto}

Una vez establecidas la idea principal y la idea secundaria del texto, así como mostrada la necesidad de regresar a aquellos conocimientos que nos pueden permitir entenderlas, se hace palpable un problema de procedimiento, y es el de saber si para alcanzar la unidad de la concepción kantiana de la educación, puede establecerse una idea-esencial, o idea-marco, determinante de los distintos análisis que el texto exige para su comprensión o, por el contrario, la lectura del texto tiene que seguirse exclusivamente en la forma de análisis secuenciales. Si es posible el primer procedimiento, y el análisis de los elementos puede entenderse en relación con dicha idea-marco, el texto se muestra dotado de una estructura esencial, en cuanto las otras

14 PEIRCE, Ch. S. (1931-35): Collected Papers of Charles Sanders Peirce (seis volúmenes), editados por Charles Hartshorne y Paul Weiss, Harvard University Press. Cfr. vol. 5 y 6. Se ha discutido mucho el carácter subjetivo, intencional y estético de la verdad en Peirce, pero no cabe duda que exigió que ésta se entendiera como el principio límite, regulador de la práctica, establecido de forma lógica.

Rhela. Vol. 13. Año 2009, pp. $241-264$ 
ideas tienen que referirse al marco que ésta constituye como partes suyas, lo que permitirá saber sobre las conexiones que pueden tener lugar entre ellas, de forma que se muestre su constitución esencial, y poner de relieve su sentido profundo.

En la obra de Kant existe esa idea-marco, pues regresando más allá de la clasificación inicial de la educación en: fisica/moral, se encuentra una noción que permite abarcar ambos términos de la oposición: la de naturaleza humana. Esta noción que en la Ilustración se presenta como problema (pero que sigue siendo muy actual ${ }^{15}$ y discutida, por cierto), no sólo constituyó la base del desarrollo del Tratado de la Naturaleza Humana de Hume, a quien Kant no cita, sino también la de la obra pedagógica de Rousseau, a quien nuestro autor sigue en ciertas cuestiones. Su concepción kantiana supone cancelar los conceptos anteriores, pues, mientras Rousseau ${ }^{16}$ consideraba que la naturaleza humana es buena y que es la cultura, la civilización, la entrada en sociedad del hombre, la que la pervierte, el concepto de naturaleza humana que preside la pedagogía de Kant no acepta la bondad de un estado primigenio, ni su perversión por la entrada en sociedad, sino que considera que la naturaleza humana se caracteriza por la existencia de condiciones que no se pueden alterar, y gérmenes que, a diferencia de los animales, se pueden y es necesario desarrollar. Esta idea de la naturaleza humana es la que hace posible considerar como transcendental la noción kantiana de proyecto educativo.

La naturaleza humana para Kant se desdobla en dos: la naturaleza del cuerpo y la naturaleza del espíritu, cuya relación tiene lugar por medio de la educación. La educación de esta naturaleza busca lo mismo en sus dos aspectos: regularla, es decir, someterla a leyes. Pero, el ser humano es algo más que un ser constituido físicamente, pues su espíritu no es sólo un espíritu atado a leyes instintivas, un espíritu animal, sino que es un ser libre (noúmeno) ${ }^{17}$ que por sí mismo ni sabe, ni puede saber, lo que esto significa, por ello si bien en la educación: "Es preciso desbastar la incultura del hombre a causa de su inclinación a la libertad, "18 ésta no puede perderse al reglar su naturaleza, como entendía Rousseau que sucede, sino que, al contrario, la regulación tiene que tener por finalidad la manifestación de la forma moral, es decir, de la capacidad práctica para establecer principios propios y del género humano, lo que requiere aprender a extraer las reglas de las acciones. Por ello, es la educación la que puede formar, hacer comprensible y cognoscible el carácter del hombre, es decir, al ser humano como ser libre, con capacidad para constituir principios propios. ${ }^{19}$ El fin de la educación ha de

15 Una negación actual de la naturaleza humana es la que realiza Steven Pinker. PINKER, S. (2007) La tabla rasa: la negación moderna de la naturaleza humana, Barcelona, Paidós.

${ }^{16}$ ROUSSEAU, J.J, Op. Cit.

${ }^{17}$ El noúmeno constituye, según la Crítica de la Razón Pura, el límite del conocimiento. Esta tesis kantiana proviene de que, lo mismo que Locke, entiende que hay que establecer límites al conocimiento; el límite sensible son los fenómenos, el límite intelectual la cosa en sí o noúmeno.

18 Puede decirse que la tesis que resume la concepción kantiana del ser humano es la que expresa de la forma siguiente: "Únicamente por la educación el hombre puede llegar a ser hombre. No es, sino lo que la educación le hace ser." Kant, I. Pedagogía, p. 31.

19 "El carácter significa que la persona deduce la regla de sus acciones a partir de sí misma

$y$ de la dignidad del género humano...es el modo de ser de su voluntad, sea bueno o 
ser precisamente éste: formar el carácter, nuestra capacidad para darnos principios de acción, lo que exige poseer una conciencia moral de la ley que permita saber cómo aplicar nuestras acciones según la ley y como orientar la ley según nuestras acciones, es decir, que llegue a transformarse en conciencia religiosa, lo que supone que la religión sea una religión razonada, o lo que es lo mismo, ordenada según leyes lógicas.

La educación es un arte, el de lograr el mejor desarrollo posible de la naturaleza "humana, " ${ }^{20}$ por lo que tiene que depender de un plan trazado de forma razonada y razonable, siendo el que Kant propone comenzar con el cuidado, proseguir instalando en el individuo mecanismos de respuesta respecto de lo útil o perjudicial, hasta alcanzar el nivel de comprensión, aplicación y formulación de conceptos.

La consideración de la naturaleza humana: corporal y espiritual, como forma esencial o idea-marco, es la que permite entender la secuencia de ideas expuesta en el texto del modo siguiente. Lo físico es común a seres humanos y animales, pero el hombre es la única criatura que ha de educarlo, pues es el único ser que "... no tiene ningún instinto, y ha de construirse el mismo su plan de conducta." ${ }^{21}$ Ahora bien, en tanto que para Kant lo fisico comprende tanto el cuerpo como el espíritu, la educación de ambos siempre tiene que estar precedida y guiada por el cuidado (Wartung), por lo que puede decirse que el cuidado constituye la primera conexión entre ambos, lo corporal y lo espiritual, pero de forma fisico-mecánica. Si se pretende educar, el cuidado no

\footnotetext{
malo." Kant, I. Op. Cit, p. 106. Que Kant sostenga que el carácter puede formarse, se ha hecho depender directamente de su seguimiento de la obra de Rousseau y de su concepto de estado de naturaleza. Es porque Rousseau entiende que en este estado no existe orientación moral, pues no existe la dicotomía bueno/malo, por lo que hay que suponer que es la educación social la que dota al individuo de carácter, en tanto que éste depende de la necesidad de saber lo que supone elegir. Pero, igualmente parecen estar influyendo sobre su teoría los planteamientos empiristas, en concreto el de Locke quien sostenía que el espíritu humano era una tabula rasa, (Cfr. Locke, J. (1998): Ensayo sobre el entendimiento humano. Madrid, Editora Nacional), aunque no en toda su extensión, pues Locke no acepta la existencia de condiciones naturales a priori, sino en el sentido de considerar la educación como un proceso de aprendizaje, tesis presente en la obra en cuanto sostiene que la enseñanza moral activa, positiva (no la pasiva, negativa) no puede enseñarse desde el inicio de la formación. Por otra parte, aunque Kant en la Crítica de la Razón Pura distinga entre carácter empírico (fenoménico y ligado a leyes causales) y carácter inteligible (nouménico y libre), se opone completamente a la de Schopenhauer, pues éste usa la distinción para probar que la libertad no existe, dado que el carácter esencial del individuo nace con él y es inamovible, y aunque pueda variarse y modularse su carácter empírico, esto no afecta más que a condiciones empíricas. Por el contrario, Kant entiende que la libertad (la capacidad moral) no depende de la posibilidad de variación del carácter inteligible (que nos es desconocido), sino de la posibilidad de lograr su manifestación, por medio de la educación, en el campo de los fenómenos. (Véanse: Kant, I. (1978) Crítica de la Razón Pura. Madrid: Alfaguara, pp. 467-469; SCHOPENHAUER, A. (2004): El Mundo como voluntad y como representación. Madrid, Trotta.

${ }^{20}$ Uno de los problemas principales que encierra la educación es que el ser humano no puede educarse a sí mismo, por ello es fundamental que el educador esté, a su vez, bien educado: "Se ha de observar que el hombre no es educado más que por hombres, que igualmente están educados. De aquí, que la falta de disciplina y de instrucción de algunos, les hace también, a su vez, malos educadores de sus alumnos." Kant, I.: Pedagogía, pp. 31-32.

${ }^{21}$ Kant, I. Op. Cit, p. 30.
} 
puede fundarse en el mimo, ni buscar la comodidad, sino que tiene que fundarse en la disciplina, que es la base para lograr convertir la animalidad en humanidad, y el salvajismo (o barbarie) en cultura, es decir, intentar que sea posible alcanzar la mejor formación e ilustración del ser humano. ${ }^{22}$

La disciplina es la parte negativa de la educación por la que se somete la naturaleza a leyes y reglas, es decir, se enseña lo que no se puede hacer, y tendrá que irse imbricando con la instrucción, la parte positiva de la educación que, si bien ha de seguir siendo mecánica, ${ }^{23}$ tiene que permitir adquirir al individuo de forma razonada los principios en que se basa la disciplina. En cuanto ninguna de ellas puede llegar a superar el nivel de dar leyes a la libertad, es necesario que ambas se entrelacen con la cultura para situar al ser humano en el contexto de lo hecho, pues éste es el que permitirá orientarse $y$ saber dirigir, es decir, utilizar los principios como guía de la práctica, ${ }^{24} \mathrm{y}$ dar paso a una educación moral que lleve al individuo a constituir sus propios principios.

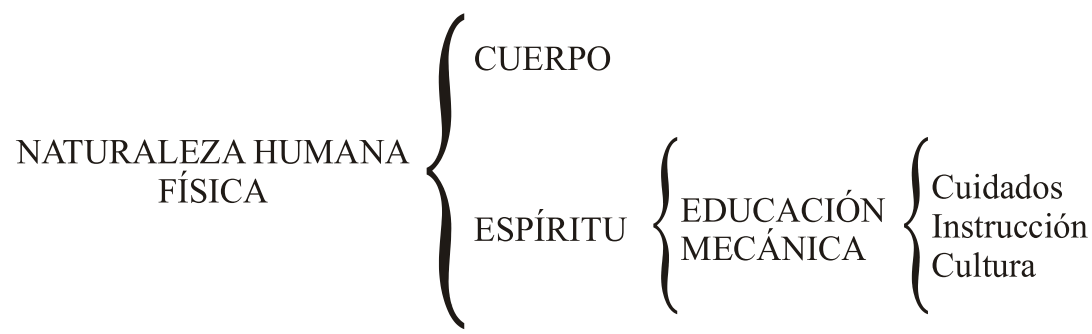

Esquema (2)

La exposición de Kant tras su aparente sencillez es muy complicada, lo que obedece a su intento de mostrar que la educación no puede consistir en la simple repetición monótona de unas reglas, y que si bien en ella hay que proceder según etapas o períodos de menos a más, hay que ir imbricando en la educación puramente mecánica del cuidado y la instrucción formas de razonamiento que pertenecen a momentos superiores, lo mismo que en los inicios del razonamiento tienen que introducirse las formas culturales, y en éstas las morales. ${ }^{25}$

De esta forma, en su inicio, la educación del cuerpo y del espíritu tiene que ser educación-física, esto es, mecánica, tanto en la disciplina (cuidado) como en la

\footnotetext{
22 "El que no es ilustrado es necio, quien no es disciplinado es salvaje". Kant, I, Op. Cit, p. 32.

${ }^{23}$ Por educación mecánica entiende Kant tanto la que procede según mecanismos, como la que sigue el método-catequístico que, contrariamente al método-socrático, no se preocupa porque el alumno descubra de la razón, sino porque siga la norma o ley.

${ }^{24}$ Kant, I. Op. Cit, p. 40

${ }^{25}$ Cuando Kant distingue entre el cuidado, la instrucción, y la moral, es porque entiende que ésta última sólo es propiamente moral si es autónoma, es decir si el sujeto puede darse y saber los principios rectores de su acción. No distingue las formas mecánicas educativas, de la moral heterónoma, es decir, de aquella moral en el sujeto sigue los principios de autoridad. En
} 
instrucción (razones), siendo su característica que en ella al individuo no se le lleve a comprender los principios que fundan la educación, sino que simplemente se le enseñe que es bueno y qué malo, que beneficioso y qué perjudicial. Pero, lo mismo que en el cuidado tienen que imbricarse la comprensión de razones, en la instrucción tiene que incorporarse el contexto cultural, por el que se abre al individuo la complejidad de lo social, y en éste tienen que introducirse las leyes morales. Así, es preciso que con el cuidado se solape la enseñanza razonada; con ésta el seguimiento de leyes y, con ésta, la búsqueda de principios, pero siempre teniendo en cuenta que, salvo en la enseñanza propiamente moral, no se puede pasar de señalar las normas y leyes a seguir en la acción. Por tanto, los tres tipos de educación nunca pueden estar separados, sólo que en la educación fisica se somete la libertad del individuo a leyes sin razonamiento, mientras que en el caso de la formación cultural se dan leyes a la libertad de forma razonada, y en el caso de la formación moral es el individuo quien tiene que establecer los principios, o criterios, a seguir. ${ }^{26}$ De ello, resulta que según Kant la educación del cuerpo y del espíritu es fisica si sólo se refiere a la naturaleza, fisico-cultural si se refiere a la relación de la naturaleza del individuo y la sociedad, y moral si se refiere a la libertad, siendo esta última muy necesaria, pues, según la educación recibida:

Un hombre puede estar fisicamente muy cultivado, puede tener un espiritu muy formado, pero puede estar moralmente muy mal educado y ser una mala criatura. ${ }^{27}$

Que Kant no acepte, como Rousseau, un estado primigenio en que equivalga naturaleza y bondad, le lleva a sostener no sólo que hay que desarrollar los gérmenes que se encuentran en él, sino también que el ser humano no es por naturaleza un ser moral, y que realmente sólo lo será cuando logre saber en qué consisten los conceptos de deber y de ley. Si la postura racionalista de Kant se muestra en la necesidad de aceptar condiciones físicas previas (corporales y espirituales), su empirismo se manifiesta en la exigencia de que en cada etapa de formación se permita y logre que el individuo ponga en relación saber y poder, pues el valor transcendental de la educación supone

\footnotetext{
el texto no hace alusión expresa a esta distinción, que si se halla expuesta implícitamente; su explicación se encuentra en la Crítica de la Razón Práctica. En este sentido la concepción kantiana no estaría en desacuerdo con las actuales de J. Piaget, W. Köhler o J. Habermas, quienes entienden que la moral se adquiere y desarrolla por influencia del entorno, salvando, por supuesto, la diferencia entre los tipos de estudio y los medios utilizados.

${ }^{26}$ La distinción que se encuentra tras esta forma de entender la educación, como el paso de seguir a encontrar leyes, es la relativa a la oposición: juicio determinante juicio reflexionante. El primero consiste en conocer la ley general y saber cuando un particular puede subsumirse en ella, el segundo exige saber encontrar la ley cuando sólo se dan los particulares. En éste último funda Kant el gusto. Cfr. KANT, I. (1958): Crítica del Juicio, Madrid, Victoriano Suárez, 2 vol., vol. 2, pp. 507-508. Del juicio reflexionante, en cuya base está el gusto, depende toda innovación. El gusto tiene que educarse lo mismo que el entendimiento (conocimiento de lo general), razón (facultad del fundamento, o comprensión de la unión de lo general y lo particular), pero en su caso es particularmente fundamental una educación de los sentidos de lo haga exacto, y no sólo fino o delicado (Ver: Kant, I, Pedagogía, pp. 59-66).

${ }^{27}$ Kant, I, Pedagogía, Op., cit, p. 61.
} 
no tan solo la realización de un esfuerzo, sino también que el ser humano sepa el valor de su esfuerzo, y tenga satisfacción por su realización, lo que el niño tiene que comprender lentamente.

Por tanto, la educación de la naturaleza tiene que comenzar desde el nacimiento, y exige que las personas que le cuidan sepan que su cuerpo y su espíritu necesitan los mismos cuidados para formar su naturaleza, pero que además es un ser libre, lo que supone que no es suficiente lograr que forme hábitos o se someta a costumbres, sino que también necesita una educación moral que le permita ejercer su libertad. La educación de la naturaleza humana, se halla encaminada a lograr que el ser humano sea un ser fuerte y resistente corporal y espiritualmente, no un ser mimado, débil e indolente; por ello, en la educación física es fundamental que el ser humano sienta la coacción, la oposición de su misma constitución, del medio y de los otros, de la sociedad, para lograr realizar lo que desea, siendo los mecanismos de respuesta al medio la forma de que se vale esta educación para procurar que el ser humano desarrolle aquellas condiciones naturales para las que se halla mejor dotado, y que le son más propias.

Así, la educación de un ser humano para ser completa, no puede ser sólo mecánica; dotar al individuo de mecanismos de respuesta sólo permite amaestrarle o adiestrarle, que es lo mismo que se hace con los animales; por ello, la educación tiene que ser también razonada de manera que procure su ilustración, es decir, que le enseñe a pensar. Ambas formas de educación son y tienen que ser coactivas, y de saber ejercer ésta depende poder lograr un individuo corporal y espiritualmente bien formado, o un individuo débil e indolente, o sólo preocupado del qué dirán, inclinado al disimulo y a las emociones internas, la agresividad o la adulación. Es preciso que el ser humano sienta y conozca qué relación se presenta en cada momento entre su libertad y la coacción que otro, sea el ambiente, otro individuo o la sociedad, ejerce sobre él, es decir, que pueda alcanzar un grado de saber que le permita decidir racionalmente qué puede hacer en cada momento. Por ello, la educación de la naturaleza humana, tanto corporal, como del espíritu, tiene que encaminarse a que el ser humano aprenda a trabajar, a aplicar mecánica y/o comprensivamente los principios, pues sólo se aprende aquello que puede hacerse,$^{28} \mathrm{y}$ va a necesitar trabajar para ganar su sustento.

La disciplina tiene que ser escolar y libre, pues, como sólo puede someter a reglas mecánicamente, hay que ir imbricando en ella el plano ideal de la cultura para ir introduciendo al niño en la formación de razones y en sus posibles variaciones, es decir, mostrarle el ámbito social. La disciplina como cultura libre es un juego, la escolar tiene que ser cultura coercitiva, tiene que sentirse que es un trabajo, que exige el cumplimiento de obligaciones que han de realizarse aunque no satisfagan, pues su utilidad no se va a mostrar de forma inmediata, pero esta coerción nunca tiene que llegar a esclavizar o a romper la voluntad del individuo, pues en este caso deja de ser educación. El juego es el lugar y el momento de placer para el individuo, lo que no quiere decir que no tenga reglas, ni fines, sino que en él se antepone el placer a las

${ }^{28}$ En esta apreciación de Kant resuena la idea del verum est factum de Vico.

Rhela. Vol. 13. Año 2009, pp. 241 - 264 
reglas, pero siempre para fortalecer la naturaleza y nunca para forzarla, por ejemplo, haciendo de la gimnasia un instrumento para el dominio del cuerpo, pero no para producir una gracia forzada. Jugando el ser humano aprende multitud de habilidades: lanzar, correr, ejercitar los sentidos y complementarlos, rapidez mental en el cálculo, memoria que permite recordar de diversas formar, por ejemplo, la localización, etc.

La disciplina e instrucción de las facultades del espiritu, tanto de las inferiores como de las superiores, tiene que estar también fundida con la introducción del individuo en la cultura y en la sociedad, y siempre teniendo en cuenta el principio de que para saber hay que producir. La formación de las facultades inferiores: los sentidos, la imaginación, la memoria, el ingenio, y la atención, tiene que estar presidida por la adquisición de rapidez y flexibilidad en la adquisición de reglas e imágenes, y encaminada a fortalecer la aplicación del sentido interno a los objetos impidiendo tanto una total divagación, como una fijación excesiva. La educación de las facultades superiores: entendimiento, juicio y razón, tiene que partir sólo de enseñar y aprender a reflexionar sobre lo que tiene lugar según la relación causa-efecto, no de intentar lograr una razón especulativa, por lo que es necesario servirse de imágenes y cosas de manera que el individuo tenga una base para comprender los principios que se enseñan, y que estos no sean para él sólo palabras vacías, lo que se logra, en unos casos, recurriendo a ejemplos en que se muestre la realización de una regla, en otros, extrayendo reglas de casos particulares.

Kant señala expresamente la necesidad de educar los sentimientos del individuo, siendo ésta fundamental dado que es absolutamente necesario que el ser humano no deje nunca de ser sensible, pero sí que logre un equilibrio en sus sentimientos que impida el dominio de una voluntad fuera de todo control frente al libre ejercicio de la razón. Pasiones y sentimientos como la envidia, la humildad, el orgullo, la vergüenza, la confianza, la caridad, etc., dan lugar a vicios o virtudes, según sea el comportamiento al que se deben, por ejemplo, la humildad o modestia puede ser una virtud, pero puede generar un vicio, si resulta de un aprecio de lo propio frente a lo de los demás. El proceso y el fin de la educación de los sentimientos tiene que seguir el esquema ya señalado: de la disciplina o enseñanza mecánica, a la comprensión y aplicación de los principios, pero incorporar, como una condición fundamental para introducir al niño en la relación cultura-moralidad (aún sin pasar del nivel de subsumirlos bajo reglas), la necesidad de enseñar al individuo a guiarse por máximas, ${ }^{29}$ leyes subjetivas, que introducen en el ser humano la comprensión de lo justo y de lo injusto.

\footnotetext{
29 Las máximas, como reglas o principios morales subjetivos, son aceptadas desde la Antigüedad, pero solo cuando Bacon deja de aceptar la existencia o búsqueda de un método único, se entienden como método. (sobre el método de aforismos: Cfr.: Bacón, F.: Of de Proficiente and Advancemnt of Learnig, vol. III, p. 405, y/o De dignitate et augmentis scientiarum, vol. I, p. 665. En: The Wors of Francis Bacón, edición de J. Spedding, R. I. Ellis y D.D. Heath, Londres, 1858, reimpresión facsímil de Fromung Verlag, Stuttgart, 1963) Sobre este tema, Ver: LAFUENTE, M.I. (1986): "La reforma filosófica de Francis Bacón", en Onega, S. Estudios literarios ingleses. Renacimiento y Barroco, pp. 437-466.
} 
La noción de justicia es en el texto kantiano el principio guía de la educación de la sensibilidad humana, hasta el punto de que la relación autoridad-obediencia no puede establecerse simplemente en función de términos absolutos (obediencia ciega), sino que el sometimiento del individuo a necesidad, tiene que realizarse atendiendo a una ley universal y universalmente aplicada, de manera que toda obediencia pueda y tenga que ser razonada y recta, de otra forma no se logrará educar un ser sociable, sino producir un rebelde. Evidentemente esta noción lleva pareja la de castigo, que Kant considera que debe ser siempre y preferentemente moral, no físico; estos últimos no consiguen realmente educar, pues esto sólo es posible promoviendo la reflexión sobre la acción y sus consecuencias, no la coacción física.

La formación práctica (moral) ${ }^{30}$ se decanta en una triple dimensión: habilidad, prudencia y moral, que se corresponde con la triple clasificación dada en el esquema (1) de la forma siguiente. La habilidad, se corresponde con la formación mecánica (escolástica), y es la formación que primero hay que proporcionar al individuo y la primera que el individuo tiene que lograr, pues es la que le hará posible valerse por sí mismo para lograr sus propósitos. La segunda, la prudencia, se corresponde con la pragmática, en cuanto se entiende como la capacidad para aplicar bien la habilidad, lo que permite al individuo vivir en sociedad, y adaptarse a las orientaciones que en ella se producen para lograr sus propósitos. Proporcionar al individuo esta educación, y que éste la adquiera es fundamental, pues es en la que reside la posibilidad de ser considerado como ciudadano y participar en las tareas públicas. Por último, la educación moral forma al individuo como ser capaz de obrar libremente, le dota de valor en relación a la especie humana y, sobre todo, a la idea de humanidad como un proceso inconcluso que, por tanto, puede lograr una mayor perfección en sus individuos y en ella misma, siempre que se extiendan al mayor número de individuos los valores más sólidos y la capacidad de lograr otros nuevos y mejores.

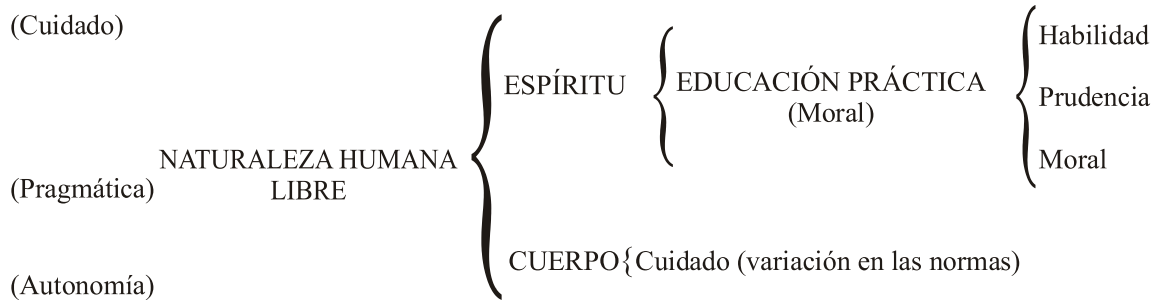

Esquema (3)

\footnotetext{
30 Razón práctica y moral son términos equivalentes en la filosofía de Kant, quien los opone a razón pura (conocimiento). Por ello, educativamente toda práctica es moral, sólo que ésta puede ser heterónoma, si se atiene exclusivamente a la autoridad, sea la nacida de las costumbres o principios (razones) sociales, o autónoma, si el individuo tiene capacidad para darse y seguir principios propios. Por ello tanto en la habilidad, como en la pragmática el individuo recibe una educación moral, sólo que heterónoma.
} 
Mientras que la habilidad, que capacita al individuo para valerse por sí mismo, y la prudencia, que le permite vivir en sociedad, requieren una formación, atención y práctica continua, desde el principio, lo que permite ponerlas en relación con la triple dimensión educativa: cuidado/instrucción/cultura, no sucede así con la educación moral que es la única que puede permitir al individuo tener un valor en y por sí mismo, pues ésta requiere poder comprender los principios, poder dárselos a uno mismo, y saber cuándo ponerlos en práctica. Kant estima que el ejercicio moral, al igual que el ejercicio fisico, no hay que llevarlo a cabo más que según lo muestre necesario el sentido común ${ }^{31}$, no en cualquier edad, sino cuando el individuo está preparado para él.

La importancia que Kant concede a la educación moral depende de que es la única que puede formar el carácter, es decir, que el individuo ordene las pasiones, las controle y les de un sentido, lo que supone que el individuo alcance una fortaleza de espíritu que le permita resistir y afrontar todo tipo de negatividades, cuya preparación se halla en la adquisición de la habilidad y el ejercicio de la prudencia. Para lograrlo, en la educación práctica, la educación que afecta al ser humano como ser libre, las distintas formas educativas tienen que solaparse (o enlazarse) de igual forma que la educación física (corporal y espiritual). Así, la educación moral tiene que entrelazarse en primer lugar con la habilidad (que psicológicamente supone el desarrollo del talento), por lo que ésta tiene que ser tan sólida que llegue a constituirse como hábito, y después tiene que unirse a la prudencia (que psicológicamente supone la formación del temperamento), y que es el arte de servirse de los otros, de penetrar en ellos mediante el arte de hacerse impenetrable. Es inútil intentar formar un carácter en los niños, pues para lograrlo el ser humano tiene que haber alcanzado la idea de deber que es la que al percibir la ley de la humanidad, es decir, la necesidad de mantener su condición de ser humano (dignidad), es capaz de mostrar al individuo los límites de su acción. Para introducir al individuo en el concepto de deber ha de buscarse, y procurar, que siga ejemplos y modelos, pero con una finalidad, la de que sepa que tiene deberes para consigo mismo y deberes para con los demás. En este sentido es fundamental que haga suya la idea de qué entender por dignidad humana, y que la aplique a sí mismo, pues es la forma de lograr que ésta presida su comportamiento y todas sus acciones. Para Kant la dignidad humana, que es la base del deber, ${ }^{32}$ está presidida por una idea, la de todos

\footnotetext{
31 Kan, I, Op. Cit., p. 46.

32 Kant no define la dignidad humana. Sólo define los imperativos: categórico e hipotético, siendo el primero el que encierra la idea de deber (véase nota 33). La razón de ello, seguramente responde a mantener como prioritaria la idea de autonomía moral, pues los principios tiene que dárselos cada uno a sí mismo; en ello radica su singularidad. Por ello también, el deber no es definido más que formalmente, y tiene que ser cada individuo el que determine en qué consiste, qué hace suyo como deber. Ahora bien, a veces suele entenderse que la dignidad humana consiste en el imperativo categórico mismo, es decir, que éste es su definición, pero entonces se entiende el imperativo como una idea límite-negativa que prohíbe que un ser humano sea medio para conseguir algo, lo que ciertamente lleva a entender a Kant como defensor de Robinson Crusoe, o del sofista Hippias de Elis, del que Marx decía que se hacía hasta su propio anillo. En el límite esto atenta contra toda sociabilidad y orden social, por ejemplo, atenta contra la división del trabajo. Esto nos obsta para que Kant enuncie ciertos deberes con los que un ser humano (ser educado) tiene que cumplir, en cuanto parte constitutiva y constituyente de la humanidad, en los que se encierra su idea de dignidad, y que pueden resumirse con la formula de: nunca rebajar la humanidad a animalidad (Ver: Kant, I. Pedagogía, p. 81-83).
} 
aquellos actos, que realmente sólo el hombre puede realizar, pues es el único ser que tiene conciencia de ellos, y que colocan al ser humano por debajo de los animales, por lo que el primer deber para consigo mismo tiene que consistir en mantener en la propia persona la dignidad humana, siendo ésta idea la única que le permite valorar (censurar o afirmar) sus acciones. Los deberes para con los demás suponen el reconocimiento y el respeto de los derechos de los otros, que no pueden confundirse con falsas obligaciones. En cuanto ser libre, la felicidad del ser humano reside para Kant en que cobre conciencia de que ésta solo depende de los principios que elija como determinantes de su acción, pues que ésta sea buena o mala, no depende de que Dios como legislador prohíba el mal, sino de qué ley (principio) elige el hombre, pues la elección le constituye en autor de esa legislación, en responsable de ella, por ello, la moral tiene que preceder a la religión, pues el culto a Dios sin moral, no es más que superstición. ${ }^{33}$

\section{CONCLUSIONES}

La obra de Kant es muy compleja, aún tras su orden. Es evidente que en su obra educativa intenta seguir y consolidar los principios ilustrados de igualdad entre los hombres y de progreso; expresamente señala que al progreso no puede atenderse sólo desde la perspectiva del Estado, sino que tiene que entenderse en cuanto aplicable a todos y cada uno de todos los seres humanos. Por ello, su obra pedagógica sólo adquiere un sentido completo cuando se considera relativamente a sus ideas críticas sobre: conocimiento, razón, libertad, juicio y gusto, pero también en relación con sus ideas sobre el Derecho Político, en el que defiende una Constitución que establezca la igualdad de derechos para todos los ciudadanos, y la necesidad de que dicha igualdad se realice de facto.

Establecer leyes para la naturaleza humana en el contexto crítico, supone cognoscitivamente, por una parte, limitar el campo en el que el conocimiento puede alcanzar un concepto ligado al orden empírico y, por otra, extender las leyes generales hasta que sea posible formar un modelo, la idea que debe guiar la acción en la búsqueda de nuevos conceptos. Pero, la búsqueda de este modelo, no es posible si el hombre no es verdaderamente libre, si no puede ser causa de nuevos principios. Ahora bien, lograr nuevos principios supone que el ser humano puede establecer leyes para su libertad, y seguirlas, de manera que se guíe en sus acciones, no por una moral heterónoma, sino por una moral autónoma, es decir, por la apreciación de lo que debe ser y hacer de acuerdo con el conocimiento y la idea de humanidad presente en él. La guía de la acción no puede descansar, si se quiere que el género humano progrese en imperativos hipotéticos, sino en el imperativo categórico. ${ }^{34}$ Lograr que el individuo adquiera una

\footnotetext{
33 Sobre la educación religiosa y su relación con la moral: ver, Kant. I.: Ibídem. pp. 86-89. Kant sostiene que es necesario promover y fomentar una moral natural, y no una sobrenatural (santidad).

${ }^{34}$ Kant formula el imperativo categórico de múltiples maneras, dos de las principales son" Obra de tal modo que uses la humanidad, tanto en tu persona como en la de cualquier otro, siempre como un fin al mismo tiempo y nunca meramente como un medio". "Obra según una máxima tal que puedas querer al mismo tiempo que sea ley universal". Los imperativos hipotéticos son, por el contrario, aquellos que indican lo que se exige como medios para conseguir cosas. Cfr. Kant. I. (2000): Crítica de la Razón Práctica. Madrid, Alianza.
} 
perspectiva lógica, epistemológica, moral y religiosa, que no le aparte de la sociedad, sino al contrario que le lleve a trabajar en su provecho propio y en el general, supone una sociedad que acepte una pluralidad de perspectivas diferentes en su seno, única forma en que el individuo puede alcanzar el concepto de su ser y destino, y que haga posible su orientación hacia la perfección de la humanidad:

Se encuentran muchos gérmenes en la humanidad; y a nosotros toca desarrollarlos, desplegar nuestras disposiciones naturales y hacer que el hombre alce su destino...El hombre...no puede hacerlo, si no tiene un concepto de él. La adquisición de éste destino es imposible para el individuo...No son los individuos, sino la especie humana quien debe llegar aqui. ${ }^{35}$

Sólo mediante la educación se puede lograr que no haya divergencia entre la búsqueda del bien particular y del bien universal, y que ambos converjan en una unidad. Que los hombres logren nivelación e igualdad en su forma de vida requiere una educación que promueva esta igualdad, y sirva de base para que los individuos y los Estados puedan lograrla. Pero, este progreso no puede lograrse si no se desarrolla de forma cosmopolita, sino limitado a una sociedad o a un Estado, por ello, la educación tiene que extenderse a toda la humanidad, única forma en que puede ser real la "unidad del yo y el otro", condición necesaria para que haya un progreso real:

Los padres cuidan de sus casas; los príncipes, del Estado. Ni unos ni otros se ponen como fin el mejor mundo (Weltsbeste), ni la perfección a la que está destinada la humanidad y para la cual tiene disposiciones. Las bases de un plan de educación han de hacerse cosmopolitamente. ¿Es el bien universal una idea que puede ser nociva a nuestro bien particular. ${ }^{36}$

Sólo la educación se preocupa realmente por el bien universal, por ello es el arte que hace progresar al género humano, aunque sea muy despacio ya que no puede realizar una transformación inmediata, sino que esforzadamente tiene que comenzar por lograr la cultura de los particulares e irse extendiendo a todo lo demás, desde la organización de las escuelas hasta todo lo que afecte al comportamiento, relación y orden, entre los seres humanos.

En este sentido Kant aboga porque se potencie la escuela pública, de las que en su tiempo existían pocas, y pretende que en ellas no se limite la educación a disciplina e instrucción, formas que solo pueden llega a dar leyes a la libertad, sino que se alcance la educación moral, que debe ser educativamente la preocupación fundamental, pues es la única que puede llevar al hombre a una de las condiciones más necesarias para la perfección de la humanidad: la filantropía, sentimiento que sólo desarrolla la moral y que lleva al ser humano a interesarse y realizar acciones en beneficio de los demás, de

35 Kant, I, Pedagogía, pp. 34-35.

${ }^{36}$ Ibídem, p. 36

Rhela. Vol. 13. Año 2009, pp. $241-264$ 
la humanidad. En este caso, el ejemplo de centro educativo era para Kant el Instituto de Dessau, pues consideraba que de forma organizada unificaba buenas intenciones y capacidad para obrar bien, lo que pensó que permitiría disponer en muchas partes de muchas y buenas escuelas, y de forma rápida. ${ }^{37}$ De ahí, que el proyecto educativo kantiano resulte una llamada a la conciencia de los poderes públicos, de la sociedad y de los individuos ilustrados, para que no se preocupen tan sólo de lograr el bien inmediato, sino que hagan posible una educación que promueva el progreso de todos los seres humanos.

De esta forma, la idea general a la que el texto nos remite no es la de formar a un ser humano, un individuo, capaz de superar por su propio esfuerzo el estado vergonzoso y lastimoso de la humanidad, sobrepasándolo por alcanzar un saber y comportamiento superior, idea que será la que presida la idea de super-hombre (Über-mensch) de Nietzsche. Esta idea semejante a la del mito platónico de la República, en que un esclavo atado al fondo de la cueva se libera y conoce la verdadera realidad, sólo lleva al encogimiento de hombros de los demás, pues resulta incomprensible para ellos; su resultado es la imagen de Zaratustra paseando por el mercado, como Sócrates en Atenas, siempre con una pregunta sin respuesta en los labios, y un candil en la mano, buscando a alguien capaz de diálogo y comprensión, a la búsqueda de una solución. El proyecto kantiano se presenta, más bien, como aquél que intenta lograr que los individuos alcancen principios y reglas capaces de permitir una acción racional, y en este sentido se aproxima al proyecto dialógico que en filosofía social ha promovido la pragmática transcendental de Apel y Habermas. Realmente, no puede ser de otra forma porque este proyecto se presentó, ya en sus inicios, como un transformado de la filosofia kantiana que, partiendo del lenguaje y la acción, pretende mostrar las reglas útiles y válidas para una acción racional de cualquier individuo en cualquier sociedad. Pero, tanto el proyecto kantiano, como el pragmático, plantean problemas fácticos todavía hoy irresolubles que provienen del carácter universal que la moral exige, es decir, de que la exigencia para que tenga lugar una práctica racional es que la moral sea universal o no sea moral, sino costumbre, hábito, etc. Señalaremos algunos de estos problemas, en relación con el proyecto kantiano, tanto en su momento histórico, como en la actualidad.

El proyecto kantiano se quiebra, tiene un límite todavía hoy no superable, dado que en él se manifiestan problemas muy profundos que no pueden resolverse con una simple extensión o adecuación, uno de ellos es que el modelo que debe servir de guía a la educación es, según Kant, el modelo europeo en función del cual, y porque no se adecuan a él, considera salvajes a todos los otros pueblos, ${ }^{38}$ problema que hoy está poniendo de manifiesto la filosofía latinoamericana actual. ${ }^{39}$ Otro es la exclusión: que

\footnotetext{
${ }^{37}$ Ibídem, pp. 95-97.

38 "Se ve también entre los salvajes, que aunque presten servicio durante mucho tiempo a los europeos, nunca se acostumbran a su modo de vivir; lo que no significa en ellos una noble inclinación a la libertad, como creen Rousseau y otros muchos, sino una cierta barbarie; es que el animal aún no ha desenvuelto en sí la humanidad”. Kant, I, Ibídem, p. 31.

${ }^{39}$ Sobre este tema remito en particular a la obra de Enrique Dussel.
} 
afecta educativamente a la mujer, para las que, según afirma, aún no se ha encontrado un proyecto educativo apropiado a la naturaleza de su sexo, ${ }^{40}$ ya que su educación nunca debe llegar a moral universal, lo que supone tanto como afirmar que el proyecto educativo que propone es sólo y exclusivamente para el sexo masculino. Ahora bien, un examen cuidadoso de las dos exclusiones que presenta el proyecto educativo kantiano muestra que sólo excluye terminantemente a las mujeres, pues si bien puede admitir que la educación de los hombres no europeos tal vez puede adecuarse al modelo, no acepta en forma alguna que la educación de la mujer pueda realizarlo pues su carácter no puede alcanzar autonomía moral, sino todo lo más formación en el arte de agradar, y pensar sólo en cuanto puede servir para conducir de forma razonada, pero delicada, a los hombres. La educación de la mujer no puede realizar su proyecto por un doble motivo: porque no puede ser responsable de sus actos y/o porque la sociedad no puede admitir que la práctica de la mujer se transforme en regla de conducta, en ley universal.

Por otra parte, en el proyecto educativo kantiano queda también sin resolver la relación entre educación-felicidad, pues si bien hace descansar ésta en determinar el principio para obrar bien (autonomía), lo que depende de la educación, la capacidad de realización no depende sólo de la educación, sino también de la forma de vida, y aunque se pueda promover la igualdad educativa, no resulta que se pueda promover la igualdad de forma de vida, por lo que es posible que la disciplina, la civilización y la cultura que la educación impone y exige a los individuos, repercuta exclusivamente en provecho del Estado, pero no en el logro de felicidad para los individuos. Kant fue consciente de este problema, como se muestra en la siguiente manifestación:

Se puede decir en el estado presente del hombre, que la felicidad de los Estados crece al mismo tiempo que la desdicha de las gentes. Y es todavía un problema a resolver, si no seríamos más felices en el estado bárbaro en que no existe la cultura actual, que en nuestro estado presente. ${ }^{41}$

La consideración crítica de las ideas educativas kantianas muestran límites y problemas que afectan no sólo a condiciones empíricas puntuales, sino también a su forma, en tanto que la noción de educación moral para lograr la perfección de la humanidad, sin la que no hay verdadera educación, hace patente que la idea de educación, y la misma idea de humanidad, no son conceptos universales, como quería entender Kant en su propuesta. Por ello, la idea de naturaleza humana no puede ser considerada, desde el punto de vista educativo de la Pedagogía, como trascendental, sino sólo como formal. Esto supone que la única forma de mostrar todo el vigor y vitalidad del proyecto educativo de Kant, es entenderlo, no como el proyecto educativoilustrado que presenta los conceptos determinantes para la realización de la educación del ser humano en toda sus extensión, sino como la idea de un proyecto educativo, dado que, en sus propias palabras, "una idea, es el concepto de una perfección no

\footnotetext{
${ }^{40}$ Cfr. Kant, I., Pedagogía, p. 104.

41 Ibídem, p. 105.
} 
encontrada aún en la experiencia"42, pero que puede servir para regular ésta hasta lograr su realización, pues la educación sólo depende de lo que los hombres quieren que sea, y su perfección de lograr que no sea mera ingeniosidad o creencia, sino juicio exacto. Lograr que esa perfección sirva de guía para la educación de la humanidad, de forma que ésta sea universal de forma efectiva, constituye el desiderátum del pensamiento ilustrado, lo que siempre ha propiciado.

Anexos

TEXTO: Kant, I. (1983) “Tratado”, en Pedagogía. Madrid, Akal, pp. 45-66.

"La Pedagogía o teoría de la educación es o fisica o práctica. La educación física es aquella que el hombre tiene en común con los animales, o sea los cuidados. La educación práctica o moral es aquella mediante la cual el hombre debe ser formado para poder vivir, como un ser que obra libremente. (Se llama práctico a todo lo que tiene relación con la libertad). Es la educación de la personalidad, la educación de un ser que obra libremente, que se basta a sí propio, y que es un miembro de la sociedad, pero que puede tener por sí mismo un valor intrínseco.

Así, pues, esta educación se compone: a) de la formación escolástico-mecánica, que se refiere a la habilidad; entonces es didáctica (instructor); b) de la formación pragmática, que se refiere a la prudencia (ayo); c) de la formación moral, que se refiere a la moralidad.

El hombre necesita de la formación escolástica o instrucción para llegar a alcanzar todos sus fines. Le da un valor en cuanto a sí mismo como individuo. La educación por la prudencia le hace ciudadano, porque adquiere un valor público. Aprende con ella, tanto a dirigir la sociedad pública a sus propósitos como a adaptarse a ella. Finalmente, por la formación moral adquiere un valor en relación con toda la especie humana.

La formación escolástica es la primera y más antigua. Pues toda prudencia supone habilidad. La prudencia es la facultad de aplicar bien la habilidad. La formación moral es la última, en tanto que se apoya en principios que el hombre mismo debe comprender; pero hay que practicarla desde luego, igual que la educación física, mientras sólo descanse en el sentido común; de otro modo, fácilmente arraigarían las faltas, en las que todo esfuerzo de la educación es inútil. En cuanto a la habilidad y a la prudencia, ha de ser continua labor. Apenas si vale más, ser de niño, hábil, prudente, benigno, astuto, al modo de un hombre, que infantil de carácter cuando adulto.

\section{FUENTES}

Kant, I. (1963): Ausgewählte Schriften zur Pädogogik und ihrer Begründung. Ed. H.H. Groothoff/E. Reimers. Pardenborn: Schöninght. Esta edición es la referencia básica de la obra pedagógica de Kant.

\footnotetext{
${ }^{42}$ Kant, I, op. cit., p. 33.
} 
Principales Obras Traducidas: del período pre-crítico

(1961): Disertación inaugural (De mundi sensibilis atque intelligibilis forma et principiis) (1770). Madrid: CSIC.

(1969): Historia general de la naturaleza y teoría acerca del cielo, Buenos Aires, Júarez.

(1974): Nueva dilucidación de los primeros principios del conocimiento metafísico. Caracas, Universidad Central de Venezuela.

(1987):Los sueños de un visionario explicados por los sueños de la metafísica. Madrid, Alianza.

(2008) Observaciones sobre el sentimiento de lo bello y lo sublime. Madrid, Alianza Editorial.

\section{Del período crítico}

(1982) ¿Qué significa orientarse en el pensamiento? Buenos Aires, Leviatán.

(1983) Pedagogía. Madrid, Akal.

(1986) La religión dentro de los límites de la mera razón. Madrid, Alianza.

(1987) Los progresos de la metafisica desde Leibniz y Wolff. Madrid, Tecnos.

(1991) Opus postumum (colección de obras inconclusas). Barcelona, Anthropos.

(1991) Antropología en sentido pragmático. Madrid: Revista de Occidente.

(1994) Fundamentación de la metafisica de las costumbres. Madrid, Espasa-Calpe.

(1999) El conflicto de las facultades. Madrid, Trotta.

(1999) Crítica del juicio. Madrid, Espasa-Calpe.

(2000) Crítica de la razón práctica. Madrid: Alianza.

(2000) Lógica. Madrid, Akal.

(2003) Crítica de la razón pura, Madrid, Alfaguara.

(2007) ¿Qué es la ilustración y otros escritos de ética política y filosofia de la historia? Madrid, Alianza Editorial.

\section{SELECCIÓN BIBLIOGRÁFICA}

ÁLVAREZ DOMÍNGUEZ, I. (1985): La filosofia kantiana de la historia. Madrid, Universidad Complutense.

ARANA, J. (1982): Ciencia y metafisica en el Kant precrítico. Sevilla, Universidad de Sevilla. AUBENQUE, P. (1975): "La prudence chez Kant”. Revue de Métaphysique et de Morale.

BOROWSKI, L.E. (1993): Vida y carácter de Kant. Madrid: Tecnos.

CASSIRER, E. (1968): Kant, vida y doctrina, México, F.C.E.

COLOMER, E. (1986): El pensamiento alemán de Kant a Heidegger. Barcelona, Herder.

DELEUZE, G. (1974): Spinoza, Kant, Nietzsche. Barcelona, Labor.

GARCÍAMORENTE, M. (1975): La filosofia de Kant, una introducción a la filosofia. Madrid, Espasa Calpe.

GÓMEZ CAFFARENA, J. (1984): El teísmo moral de Kant, Madrid, Cristiandad.

HARTNACK, J. (1984): La teoría del conocimiento de Kant. Madrid, Cátedra.

HEIDEGGER, M. (1973): Kant y el problema de la metafisica. México, F.C.E.

HELLER, A. (1984): Crítica de la Ilustración. Barcelona, Península. 
HERRERO, J. F. (1975): Religión e historia en Kant. Madrid, Gredos.

HOEFFE, O. (1986): Immanuel Kant. Barcelona, Herder.

JIMÉNEZ MORENO, L. (1995): Kant. Madrid, Ediciones del Orto.

KOERNER, S. (1977): Kant. Madrid, Alianza Editorial.

LACROIX, J. (1969): Kant y el kantismo. Buenos Aire, Sudamericana.

LAFUENTE, M. I. (1990): Ideas, principios y dialéctica. León: Contextos. Universidad de León.

MARTÍNEZ MARZOA, F: (1989): Releer a Kant. Barcelona, Anthropos.

MOYA, E. (2003) ¿Naturalizar a Kant? Criticismo y modularidad de la mente. Madrid: Biblioteca Nueva.

MOYA, E. (2008) Kant y las ciencias de la vida. Madrid: Biblioteca Nueva.

MUGUERZA, J. y RODRÍGUEZ ARAMAYO, R.(1989): Kant después de Kant. Madrid, Tecnos.

PALACIOS, J. M. (1979): El idealismo trascendental: teoría de la verdad. Madrid, Gredos.

RÁBADE, S. y LÓPEZ MOLINA, A.M. y PESQUERO, E. (1987) Kant Conocimiento y realidad. Madrid, Cincel.

RODRÍGUEZ ARAMAYO, R. Vilar, G. (1982) En la cumbre del criticismo. Barcelona: Anthropos.

RODRÍGUEZ GARCÍA, R. (1983): La fundamentación formal de la ética. Madrid, Universidad Complutense.

STRAWSON, P.F. (1975): Los límites del sentido, ensayo sobre la crítica de la razón pura de Kant. Madrid, Revista de Occidente.

TERUEL, P. J. (2008): Mente, cerebro y antropología en Kant. Madrid, Tecnos.

TORRETI, R. (1967): Manuel Kant. Estudios sobre los fundamentos de la filosofia crítica. Santiago de Chile, Universidad de Chile.

UREÑA, E.M. (1979): La crítica kantiana de la sociedad y la religión. Madrid, Tecnos.

ZUBIRI, X. (1980): Cinco lecciones de filosofía, Madrid, Alianza.

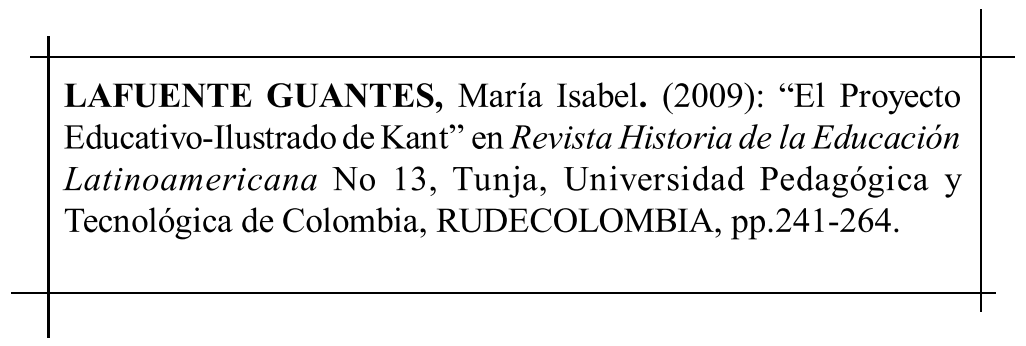

Rhela. Vol. 13. Año 2009, pp. 241 - 264 